Journal of Animal and Veterinary Advances 10 (17): 2244-2247, 2011

ISSN: $1680-5593$

(C) Medwell Journals, 2011

\title{
Sequence Variation in Perforin-Like Protein 1 Gene among Six Toxoplasma gondii Strains
}

\author{
${ }^{1,2}$ H.K. Yan, ${ }^{2}$ H.Q. Song, ${ }^{1,2}{ }^{2}$. Zhou, ${ }^{1,2}$ D. Ren, ${ }^{2}$ D.H. Zhou, ${ }^{2}$ M.J. Xu, \\ ${ }^{1}$ R.Q. Lin, ${ }^{2}$ X.Q. Zhu and ${ }^{1,2}$ Z.G. Yuan \\ ${ }^{1}$ College of Veterinary Medicine, South China Agricultural University, \\ 483 Wushan Street, Tianhe District, Guangzhou, 510642 Guangdong Province, P.R. China \\ ${ }^{2}$ State Key Laboratory of Veterinary Etiological Biology, \\ Key Laboratory of Veterinary Parasitology of Gansu Province, \\ Lanzhou Veterinary Research Institute, CAAS, Lanzhou, 730046 Gansu Province, P.R. China
}

\begin{abstract}
Perforin-like Protein 1 (PLP1) plays an important role in the invasion process of $T$. gondii. In this study, we examined sequence variation in the $P L P 1$ gene among six $T$. gondii strains from Guangzhou and Panyu in Guangdong, Suhe in Henan, Huzhu in Qinghai provinces of China, France and the USA, representing different genotypes. The PLP1 gene was amplified from the $>6$ strains by Polymerase Chain Reaction (PCR) and the amplicons were cloned and sequenced. The length of all of the PLP1 sequences was $3453 \mathrm{bp}$, consistent with that available in GenBank (EF 102772.2). In total, there were 42(1.22\%) variable nucleotide positions among the six $P L P 1$ gene sequences and the 22 of which represented transversions. The $\mathrm{A}+\mathrm{T}$ contents of the sequences was $48.3 \sim 48.9 \%$. Intra-specific nucleotide variation was related mainly to changes at the 2 nd and 3 rd codon positions while fewer changes were detected at the 1 st codon position. These results demonstrated that sequence variation in $P L P 1$ gene among the six $T$. gondii strains was low and the $P L P 1$ gene may not be an appropriate marker for the studies of genetic variation among $T$. gondii strains.
\end{abstract}

Key words: Toxoplasma gondii, toxoplasmosis, Perforin-like Protein 1 (PLP1) gene, genetic variation, sequence, China

\section{INTRODUCTION}

Toxoplasmosis is a parasitic disease caused by the intracellular protozoan parasite Toxoplasma gondii. It is one of the most epidemic parasitic diseases in human beings and warm-blooded animals. It is an opportunistic disease which is often lethal for patients with AIDS organ transplant recipients and those with neoplastic diseases such as birth defects, retinitis and brain damage if acutely infected via vertical transmission (Montoya and Liesenfeld, 2004). Furthermore, toxoplasmosis can result in serious economic losses to livestock industries (Buxton, 1998; Dubey et al., 2005; Zou et al., 2009).

Perforin (PF) and members of the Membrane Attack Complex (MAC) (complement proteins C6-C9) are poreforming proteins of the innate and adaptive immune response that constitute the founding members of the MACPF domain family (Voskoboinik et al., 2006). Perforin-like Proteins (PLPs) are expressed by many bacterial and protozoan pathogens including $T$. gondii (Kaiser et al., 2004; Rosado et al., 2008). T. gondii
Perforin-like Protein 1 (TgPLP1) deficient parasites failed to exit normally after intracellular growth, resulting in entrapment within host cells (Kafsack et al., 2009). Perforin-dependent killing of infected dendritic cells led to active egress of infectious parasites that rapidly infected adjacent effector NK cells (Persson et al., 2009).

Upon acting on infected cells via perforin-dependent pathways, $\mathrm{T}$ cells induce rapid egress of infectious parasites able to infect surrounding cells (Persson et al., 2007). All these data shows that PLPs play important roles in toxoplasmosis. However, sequence diversity in $T g P L P 1$ gene is still unknown. Therefore, the objective of the present study was to examine sequence variation in $T g P L P 1$ gene among six different $T$. gondii strains from different hosts and geographical locations which represents different $T$. gondii genotypes.

\section{MATERIALS AND METHODS}

Parasites, RNA extraction and RT-PCR: Tachyzoites of six T. gondii strains, namely $\mathrm{RH}, \mathrm{TgC7}$, PYS, TgPLh,

Corresponding Author: Z.G. Yuan, College of Veterinary Medicine, South China Agricultural University, 483 Wushan Street, Tianhe District, Guangzhou, 510642 Guangdong Province, P.R. China 
Prugniaud (PRU) and $\mathrm{QHO}$ representing different genotypes (Zhou et al., 2009, 2010) were conserved in liquid nitrogen in the Laboratory of Parasitology, College of Veterinary Medicine, South China Agricultural University (Table 1). Tachyzoites were dissolved in $38^{\circ} \mathrm{C}$ water-bath and were used to infect Kunming mice intraperitoneally. Tachyzoites were harvested $72 \mathrm{~h}$ after infection from the peritoneal fluid of mice and stored at $-80^{\circ} \mathrm{C}$. Total RNA was isolated from the tachyzoites, column-purified (MagaZorb®) Total RNA Mini-Prep kit, QIAGEN) and then eluted into $20 \mu \mathrm{L}$ RNase-free water according to the manufacturer's recommendations. RNA samples were stored at $-70^{\circ} \mathrm{C}$ until use.

RT-PCR reactions $(20 \mu \mathrm{L})$ were performed in $12 \mu \mathrm{L}$ thermal denatured $\mathrm{RNA}\left(65^{\circ} \mathrm{C}\right.$ for $5 \mathrm{~min}$ with $9 \mu \mathrm{L}$ RNasefree $\mathrm{H}_{2} \mathrm{O}, 1 \mu \mathrm{L}$ random primer, $2 \mu \mathrm{L}$ total $\mathrm{RNA}$ ), $4 \mu \mathrm{L} 5 \times \mathrm{RT}$ buffer, $2 \mu \mathrm{L}$ dNTP mixture $(10 \mathrm{mM}), 1 \mu \mathrm{L}$ RNase inhibitor (10 $\mathrm{U}_{\mu} \mathrm{L}^{-1}$ ) and $1 \mu \mathrm{L}$ ReverTra Ace in a thermocycler (biometra) under the following conditions after an incubation at $30^{\circ} \mathrm{C}$ for $10 \mathrm{~min}$ then $42^{\circ} \mathrm{C}$ for $50 \mathrm{~min}$; $99^{\circ} \mathrm{C}$ for $5 \mathrm{~min}$ and finally at $4^{\circ} \mathrm{C}$ for $5 \mathrm{~min}$.

Enzymatic amplification: The $P L P 1$ gene was amplified by Polymerase Chain Reaction (PCR) using a pair of primers (forward primer: 5'-ATGAGGTCACTCACAC ATGG (A/T/C)-3' and reverse primer: 5'-TTACAGGTCT AACAG CTTGACG(A/T/C)-3'). PCR reactions $(25 \mu \mathrm{L})$ were performed in $3 \mathrm{mM}$ of $\mathrm{MgCl}_{2}, 0.5 \mu \mathrm{M}$ of each primer, $2.5 \mu \mathrm{L}$ LA-Buffer, $0.2 \mathrm{mM}$ of each dNTPs, $1.25 \mathrm{U}$ of LA Taq polymerase (TaKaRa) and $2 \mu \mathrm{L}$ of cDNA sample in a thermocycler (biometra) under the following conditions after an initial denaturation at $94^{\circ} \mathrm{C}$ for $5 \mathrm{~min}$ then $94^{\circ} \mathrm{C}$ for $30 \mathrm{sec}$ (denaturation); $62^{\circ} \mathrm{C}$ for $30 \mathrm{sec}$ (annealing); $72^{\circ} \mathrm{C}$ for $30 \mathrm{sec}$ (extension) for 32 cycles followed by a final extension at $72^{\circ} \mathrm{C}$ for $5 \mathrm{~min}$.

Samples without $T$. gondii cDNA were included in each PCR run as negative controls. Also, host (mouse) control-DNA samples were subjected to the same amplification procedures as for parasite DNA. Each amplicon $(5 \mu \mathrm{L})$ was examined on $1 \%$ agarose gels, stained with ethidium bromide and photographed using a gel documentation system (UVItec). The DL5000 marker (TaKaRa) was utilized to estimate the sizes of the PLP1 PCR products.

Purification, cloning, sequencing and analysis of $P L P 1$ gene: Representative PCR products were purified using spin columns (Agarose Gel DNA Purification kit Ver. 2.0 TaKaRa) and the purified PCR products were ligated into the pGEM-T easy plasmid vector (Promega) according to manufacturer's recommendations. The recombinant plasmid was then transformed into JM109 competent cells
Table 1: Geographical origins, hosts of Toxoplasma gondii strains and the GenBank accession number of their Perforin-like Protein 1 (PLPI) genes

\begin{tabular}{lllll}
\hline $\begin{array}{l}\text { Sample } \\
\text { code }\end{array}$ & Genotype $^{a}$ & $\begin{array}{l}\text { Geographical } \\
\text { origin }\end{array}$ & Host & $\begin{array}{l}\text { Accession } \\
\text { no. }\end{array}$ \\
\hline TgC7 & $\# 3$ & Guangzhou, Guangdong & Cat & JF792807 \\
TgPLh & Type I & Suhe, henan & Pig & JF792808 \\
PRU & Type 2 & France & Human & JF792809 \\
PYS & $\# 3$ & Panyu, Guangdong & Pig & JF792810 \\
QHO & Type 2 & Huzhu, Qinghai & Sheep & JF792811 \\
RH & Type I & USA & Human & JF792812 \\
\hline
\end{tabular}

${ }^{\mathrm{a}}$ Zhou et al. $(2009,2010)$

(Promega) and positive transformants containing recombinant plasmids were selected by PCR amplification. Cell cultures with confirmed recombinant plasmid were sent to Shanghai Songon Biological Engineering, Biotechnology Company for sequencing.

Three colonies from each sample were sequenced from both directions. Sequences of the PLP1 gene were aligned using the computer program ClustalX 1.81 (Thompson et al., 1997), genetic distance calculation was performed using PUZZLE 4.1 (Strimmer and von Haeseler, 1996), sequence homology analysis was performed and the nucleotide composition, transition and transversion were counted using the Megalign program in the software DNA Star Version 5.0.

\section{RESULTS AND DISCUSSION}

The total RNA was prepared from six $T$. gondii strains from different hosts and geographical locations, representing different $T$. gondii genotypes (Table 1). As expected, a fragment of approximately $3450 \mathrm{bp}$ in length was amplified from cDNA sample representing each $T$. gondii strain. On agarose gels, no size variation was detected among all of the amplicons and no products were amplified from the host or no-DNA control samples (Fig. 1). Representative PCR products were purified and cloned into pGEM-T easy plasmid vector. The positive recombinant plasmids were selected by bacterial PCR amplification and sequenced.

Six PLP1 sequences of 3453 bp were obtained. Sequence comparison among the six PLP1 sequences revealed $42(1.22 \%)$ variable nucleotide positions of which 20 were transitions and 22 were transversions. The $\mathrm{A}+\mathrm{T}$ contents of the sequences was $48.3 \sim 48.9 \%$ which was lower than that of $\mathrm{C}+\mathrm{G}$ contents $(51.1 \sim 51.7 \%)$. Intraspecific nucleotide variation in PLP1 sequences was related mainly to changes at the 2 nd and 3 rd codon positions while fewer changes being detected at the 1 st codon position.

Although, only $42(1.22 \%)$ nucleotides in PLP1 sequences were different among the six $T$. gondii strains (Table 2) indicating a low sequence divergence in 


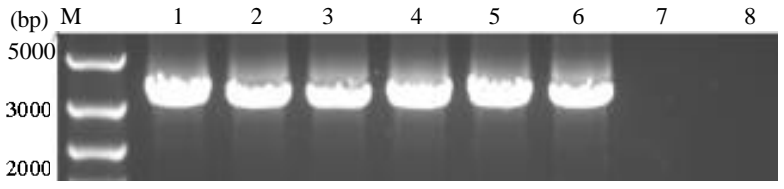

Fig. 1: Analysis of the PCR products of the Perforin-like Protein 1 (PLP1) gene among six Toxoplasma gondii strains by $1 \%$ agarose gel electrophoresis. Lanes $1-8$ represent strains $\mathrm{RH}, \mathrm{TgC7}$, PYS, TgPLh, $\mathrm{PRU}, \mathrm{QHO}$, host (mouse) control and negative (no-DNA) control, respectively. $M$ represents a DNA size marker (ordinate values in bp)

Table 2: Pairwise comparison of sequence percent identity (\%) and divergence in the Perforin-like Protein $1(P L P I)$ gene among six Toxoplasma gondii strains from China, France and USA

\begin{tabular}{lcccccc}
\hline Strains 1 & RH & TgC7 & PYS & TgPLh & PRU & QHO \\
RH & - & 98.5 & 98.2 & 98.1 & 98.4 & 98.4 \\
TgC7 & 1.5 & - & 99.4 & 99.4 & 99.6 & 99.8 \\
PYS & 1.8 & 0.6 & - & 99.0 & 99.2 & 99.4 \\
TgPLh & 1.9 & 0.6 & 1.0 & - & 99.1 & 99.3 \\
PRU & 1.6 & 0.4 & 0.8 & 0.9 & - & 99.4 \\
QHO & 1.6 & 0.2 & 0.6 & 0.7 & 0.6 & - \\
\hline
\end{tabular}

T. gondii $P L P 1$ gene, 13 nucleotides were different in the PLP1 sequences between the RH stain stored in the laboratory and the corresponding sequence of the $\mathrm{RH}$ strain available in GenBank (EF 102772.2) which may due to gene mutations induced by survival pressure in different experimental hosts.

\section{CONCLUSION}

The present study examined sequence variation in the $P L P 1$ gene among six $T$. gondii strains from different hosts and geographical locations, representing different T. gondii genotypes. The results revealed a low sequence divergence in $T$. gondii $P L P 1$ gene and the $P L P 1$ gene may not be an appropriate marker for the studies of genetic variation and virulence among $T$. gondii strains.

\section{ACKNOWLEDGEMENTS}

This study was supported in part by grants from the National Natural Science Foundation of China (Grant No. 30901067), the State Key Laboratory of Veterinary Etiological Biology, Lanzhou Veterinary Research Institute, Chinese Academy of Agricultural Sciences (SKLVEB2009KFKT014 and SKLVEB2010KFKT010), the Natural Science Foundation of Guangdong Province (Grant No. 9451064201003715), the Scientific and Technological Planning Project of Guangdong Province (Grant No. 2010B020307006), the Specialized Research Fund for the Doctoral Program of Higher Education (Grant
No. 20094404120016), the Program for Changjiang Scholars and Innovative Research Team in University (Grant No. IRT0723), the President's Funds of South China Agricultural University (Grant No. 2009K034, 5500209073 and 4100-K09320) and the Program for Science and Technology Innovation Activity of SCAU (2010).

\section{REFERENCES}

Buxton, D., 1998. Protozoan infections (Toxoplasma gondii, Neospora caninum and Sarcocystis spp.) in sheep and goats: Recent advances. Vet. Res., 29: 289-310.

Dubey, J.P., D.E. Hill, J.L. Jones, A.W. Hightower and E. Kirkland et al., 2005. Prevalence of viable Toxoplasma gondii in beef, chicken and pork from retail meat stores in the United States: Risk assessment to consumers. J. Parasitol., 91: 1082-1093.

Kafsack, B.F.C., J.D.O. Pena, I. Coppens, S. Ravindran, J.C. Boothroyd and V.B. Carruthers, 2009. Rapid membrane disruption by a perforin-like protein facilitates parasite exit from host cells. Science, 323: $530-533$.

Kaiser, K., N. Camargo, I. Coppens, J.M. Morrisey, A.B. Vaidya and S.H.I. Kappe, 2004. A member of a conserved Plasmodium protein family with membrane-attack complex/perforin (MACPF)-like domains localizes to the micronemes of sporozoites. Mol. Biochem. Parasitol., 133: 15-26.

Montoya, J.G. and O. Liesenfeld, 2004. Toxoplasmosis. Lancet, 363: 1935-1958.

Persson, E.K., A.M. Agnarson, H. Lambert, N. Hitziger and H. Yagita et al., 2007. Death receptor ligation or exposure to perforin trigger rapid egress of the intracellular parasite Toxoplasma gondii. J. Immunol., 179: 8357-8365.

Persson, C.M., H. Lambert, P.P. Vutova, I. DellacasaLindberg and J. Nederby et al., 2009. Transmission of Toxoplasma gondii from infected dendritic cells to natural killer cells. Infect. Immun., 77: 970-976.

Rosado, C.J., S. Kondos, T.E. Bull1, M.J. Kuiper and R.H.P. Law et al., 2008. The MACPF/CDC family of pore-forming toxins. Cell. Microbiol., 10: 1765-1774.

Strimmer, K. and A. von Haeseler, 1996. Quartet puzzling: A quartet maximum-likelihood method for reconstructing tree topologies. Mol. Biol. Evol., 13: 964-969.

Thompson, J.D., T.J. Gibson, F. Plewniak, F. Jeanmougin and D.G. Higgins, 1997. The Clustal-X windows interface: Flexible strategies for multiple sequence alignment aided by quality analysis tools. Nucl. Acids Res., 24: 4876-4882. 
Voskoboinik, I., M.J. Smyth and J.A. Trapani, 2006. Perforin-mediated target-cell death and immune homeostasis. Nat. Rev. Immunol., 6: 940-952.

Zhou, P., H. Zhang, R.Q. Lin, D.L. Zhang, H.Q. Song, C. Su and X.Q. Zhu, 2009. Genetic characterization of Toxoplasma gondii isolates from China. Parasitol. Int., 58: 193-195.
Zhou, P., H. Nie, L.X. Zhang, H.Y. Wang and C.C. Yin et al., 2010. Genetic characterization of Toxoplasma gondii isolates from pigs in China. J. Parasitol., 96: 1027-1029.

Zou, F.C., X.T. Sun, Y.J. Xie, B. Li, G.H. Zhao, G. Duan and X.Q. Zhu, 2009. Seroprevalence of Toxoplasma gondii in pigs in Southwestern China. Parasitol. Int., 58: 306-307. 